\title{
Inovação na fabricação de cervejas especiais na região de Belo Horizonte
}

Rubens Hermógenes Ferreira.

Mestre em Administração com ênfase em Gestão da Inovação. Psicólogo Especialista em Pedagogia Empresarial e Educação Tecnológica. Professor do ensino superior.

Maria Celeste R Lobo Vasconcelos.

Doutora em Ciência da Informação. Coordenadora do Centro de Pós Graduação da Fundação Pedro Leopoldo. Professora do Mestrado Profissional em Administração.

Valéria Maria Martins Judice.

PhD. em Políticas de Ciência e Tecnologia. Mestre em Sociologia. Especialista em Teoria Econômica. Professora Adjunta na Universidade Federal de São João Del-Rei.

Jorge Tadeu de Ramos Neves.

Pós Doutorado em Empreendedorismo e Inovação na Université de Montreal. Doutor em Génie Industriel et Gestion de L'innovation Technologique. Professor do Mestrado Profissional em Administração das Faculdades Pedro Leopoldo. Professor Associado 4 da Escola de Ciência da Informação da UFMG.

Este artigo tem como objetivo identificar os processos de inovação na fabricação de cervejas especiais na grande Belo Horizonte. Para tanto, utilizou-se conceitos como cervejas especiais, inovação, empreendedorismo e gestão do conhecimento. $O$ foco teórico foi concentrado na evolução da indústria cervejeira, no processo de inovação e nas diversas tipologias adotadas pelos autores tradicionais, que são referência no tema. Autores como Schumpeter, e os mais recentes, como Tidd, Bessant \& Pavitt (2008), auxiliaram na definição de inovação usada neste trabalho. A coleta de dados deu-se através de entrevistas com atores da produção de cervejas especiais, da observação em painel setorial, em mesa redonda em evento do setor, além de pesquisa documental. Os sujeitos pesquisados foram os atores envolvidos com 
cervejas especiais, como: microcervejeiros, homebrewers e consultores do setor. As conclusões indicam que a inovação tem sido importante para aqueles que atuam com esse tipo de cerveja, seja pela diferenciação do produto, pelo atendimento às exigências do mercado e por uma atuação incipiente em redes sociais para transmissão do conhecimento. Os resultados da pesquisa mostraram evidências da ocorrência de inovação no setor cervejeiro artesanal, em particular, as incrementais.

Palavras-chave: Inovação; Cervejas artesanais; Cultura cervejeira; Disseminação do conhecimento.

\section{Innovation in special beers brewery in Belo Horizonte's region}

This article aims to identify the innovation in special beers brewery in Belo Horizonte's region. In order to do that, concepts as special beers, innovation, entrepreneurship and knowledge sharing have been used. The literature review focused on the evolution of the brewery industry, the innovation process and the different typology used by the traditional authors who are experts on the subject. Authors as Schumpeter and Tidd, Bessant \& Pavitt (2008) have helped with the definition of innovation that was used in this paper. The data was gathered through interviews with special beers manufacturers, observation in sectorial panels, round tables in events and documental research. The researched individuals were the ones involved with special beer as: micro-brewers, homebrewers and consultants. It is concluded that the innovation has been important for those who work with this kind of beer either due to the product differentiation, the need to follow the market demands or due to the incipient participation in social networks in order to share the knowledge. The results of the research show that innovation has been applied in the handmade brewery sector especially in the incremental ones.

Keywords: Innovation; Handmade beers; Brewery culture; Knowledge sharing.

Recebido em 12.07.2011 Aceito em 12.12.2011 


\section{Introdução}

Com a globalização de mercado e as fusões de grandes cervejarias, a indústria da cerveja consolidou-se em grandes grupos pelo mundo. As três megacervejarias, as quais produzem mais de 100 milhões de hectolitros/ano, detêm quase $50 \%$ da produção mundial de cervejas, possuindo marcas distribuídas em diversos países (MORADO, 2009).

No Brasil, essa tendência de consolidação de grandes cervejarias pode ser constatada desde 1999, pelas grandes aquisições e fusões do setor como a AmBev, (AMERICAN BEVERAGE COMPANY - AMBEV, 2010) ${ }^{1}$. $\mathrm{Na}$ época, a AmBev era a $4^{\mathrm{a}}$ maior cervejaria do mundo, com aproximadamente 70 bilhões de litros vendidos por ano no Brasil, tendo sido, inicialmente, uma fusão das cervejarias Antártica e Brahma, e aquisição posterior de diversas cervejarias pelo Brasil e o mundo. Atualmente, possui fábricas em 14 países das Américas e distribuição das suas cervejas em quase todos os países, além de aquisições de grandes cervejarias.

Contrário a esse movimento de expansão, de fusões, de alianças de grandes grupos, de consumo de bilhões de litros de cerveja tipo Lager $^{2}$ e Pilsen, que devem ser consumidas de forma gelada e rápida, surge o movimento do slow beer. A filosofia deste movimento tem relação com o resgate da história, da cultura e do prazer de se fazer e beber boas cervejas, associada à gastronomia de qualidade, como propõe o movimento slow food ${ }^{3}$. Nesse contexto, ressurgiram as cervejarias artesanais e os homebrewers ${ }^{4}$, que têm como atração a produção da própria cerveja, ao contrário da maioria das cervejas produzidas pelas grandes cervejarias e disponíveis para o consumidor comum.

Observa-se que os produtores de cervejas caseiras se agrupam em associações conhecidas como Associações de Cervejeiros Artesanais (AcervAs), reunidas em diversos estados brasileiros. Em recente censo de setembro de $2010^{5}$, mais de 400 cervejeiros caseiros responderam a perguntas sobre o tempo que estão no mercado e sua produção. Os dados indicam que a atividade no Brasil é bem recente: $72 \%$ dos respondentes,

Disponível em: <http://www.ambev.com.br/Ambev/historico.aspx>. Acesso em: 26 mar. 2010.

Lager: tipos de cerveja mais consumidas no mundo a maioria delas é clara na cor, com alto teor de gás carbônico, de sabor moderadamente amargo e conteúdo alcoólico entre 3-6\% por amostra. Seu nome advém da palavra germânica lagern ("armazenar"). Disponível em: <http://www.ambev.com.br/Sociedade da Cerveja/cervejaTipos.aspx>. Acesso em: 26 mar. 2010.

3 O movimento "Slow food" surgiu na Itália como rejeição a uma loja da McDonalds inaugurada na Piazza de Spagna em Roma em 1986. O intuito era combater a padronização e baixa qualidade de refeições fast food. O movimento evoluiu em perspectivas de responsabilidade sócio ambiental, na defesa a ideia de que o indivíduo é responsável pelo processo e co-produtor do que consome (WARGAFTIG,2009).

Denominação para cervejeiro caseiro segundo (MORADO, 2009, p. 309).

AMORIM, R. 10 CENSO ACERVAS. Disponível em: <http://oglobo.globo.com/blogs/cervejaso>. Acesso em 13 out. 2010. 
isto é, 314 participantes cultivam o hobby há menos de 2 anos e apenas $6 \%, 26$ participantes, fazem cerveja em casa há mais de 5 anos.

De acordo com a análise de Rao (2010), crescem movimentos sociais nos mercados quando os participantes se sentem excluídos. Em especial, com o surgimento de inovações em produtos e hábitos sociais, emergem movimentos identitários, que se aglutinam via redes de propagação de novas culturas de consumo, novas mentalidades, atitudes e comportamentos e que buscam validá-las socialmente: "Surgem os movimentos de identidade caracterizados pelo sentimento de "nós", para desafiar organizações ou categorias dominantes e buscar concretizar novas identidades coletivas que enfatizam a democracia, a participação e o empoderamento" (RAO, 2010, p. 43).

Além do ambiente favorável para produtos diferenciados, exclusivos e de acesso limitado a pequenos grupos de apreciadores, outros fatores são importantes no advento das cervejas especiais. Dentre eles, cita-se a "diplomação em consumo" do consumidor brasileiro, cada vez mais exigente, com o paladar mais apurado e sensibilizado pela invasão das cervejas importadas no mercado nacional. Em igual importância, observase a concentração e o domínio de grandes grupos cervejeiros, resultando em um contingente significativo de mestres-cervejeiros disponíveis no mercado e aposentados advindos das cervejarias menores. Estes profissionais detêm o capital de conhecimento na produção da cerveja e continuam a participar ativamente desse movimento como consultores, instrutores de cursos para interessados, ajudando a desenvolver novas receitas de cerveja baseados na Lei da Pureza da Cerveja ${ }^{6}$ e a difundir a cultura cervejeira. A importância deste profissional chega a ter recomendações como as de Tschope (2001, p. 13): "os clientes deveriam conhecer pessoalmente o mestre cervejeiro, e com ele aprofundar-se nos conhecimentos sobre o fabrico deste líquido". Estes fazem parte do movimento das microcervejarias americanas, citado por Rao (2010), como construtores de uma causa apaixonante (contrários à cerveja da produção em massa) e apoiando-se em uma mobilização descolada (pequenos produtores que usam métodos tradicionais e técnicas artesanais para oferecer cerveja diferente, mas, trazendo diversidade cultural e local).

No Brasil, o fenômeno das microcervejarias, surgiu na segunda metade da década de 1980, com dezenas de pequenos empreendimentos que se estabeleceram principalmente no Sul e Sudeste, segundo Morado (2009). Na Região Metropolitana de Belo Horizonte (RMBH) encontram-se algumas microcervejarias, como a Falke Bier, Krug Bier, a Baker Artesanal, a Wälls, dentre outras, que produzem cervejas reconhecidas dentro e fora do país, apesar de serem regionais. Ainda nesta região, são encontradas nanocervejarias como a Küdbier, a Grimor e inúmeros homebrewers, que possuem cervejas premiadas em concursos nacionais. 
As mudanças na produção e no consumo de cervejas especiais, em Minas Gerais, indicam a hipótese de que a inovação seria um fator importante para esta alteração na forma de produção e na sobrevivência das microcervejarias. Bessant e Tidd (2009) afirmam que o lado positivo da inovação é fortemente associado ao crescimento. Novos negócios são criados a partir de novas ideias, pela geração de vantagem competitiva naquilo que a empresa pode ofertar.

O objetivo principal deste artigo é apresentar os resultados de uma pesquisa, cujo foco foi analisar como ocorre a inovação no setor de cervejas especiais na região metropolitana de Belo Horizonte, procurandose compreender quais são suas implicações para o setor e a cultura cervejeira. Para tanto, fez-se necessário atingir alguns objetivos específicos, tais como: identificar os principais atores envolvidos em cervejas especiais da $\mathrm{RMBH}$; conhecer o processo de fabricação de cervejas especiais realizados por estes atores; verificar se existem processos de inovação em cervejas especiais; e a contribuição destes atores ao acúmulo do conhecimento na produção de cervejas especiais e sua respectiva disseminação.

Para se atingir ao objetivo proposto, este artigo foi estruturado em 5 tópicos, incluindo esta Introdução. O segundo tópico apresenta os principais conceitos sobre a cultura cervejeira e sua evolução histórica e é seguido pelo terceiro tópico, que discorre sobre o processo de inovação. A metodologia é apresentada no tópico quatro, a análise e discussão dos resultados no tópico cinco, e as conclusões no tópico seis.

\section{Cultura cervejeira e sua evolução histórica}

A definição de cerveja no Brasil se dá pelo Decreto nº. 2.314, de 4 de setembro de 1997, Art. 64 (BRASIL, 1997): "Cerveja é a bebida obtida pela fermentação alcoólica do mosto cervejeiro oriundo do malte de cevada e água potável, por ação da levedura, com adição de lúpulo". Portanto, uma cerveja é qualquer uma das variedades de bebidas alcoólicas produzidas pela fermentação de matéria como amido, derivada de cereais ou de outras fontes vegetais. Cerveja especial ou artesanal é uma categoria que abriga as cervejas de qualidade superior e de alto valor agregado. Em geral, são cervejas que utilizam receitas ou processos de fabricação diferentes das de fabricação em larga escala. Essas cervejas nem sempre são chamadas de Premium e, normalmente, não se autodenominam "Especial". Tem-se como exemplos a DeuS, Eisenbahn Lust, Monasterium, Pilsener Urquel, Strong Suffolk.

Morado (2009) ressalta que, na Idade Média, a produção de cerveja era uma atividade caseira, de responsabilidade das mulheres e para o consumo da família. A preferência da mesma se dava pelo baixo custo, principalmente em relação ao vinho e servia de complemento à alimentação. Iniciativas de produção em maior escala aconteceram nos mosteiros do século VI, dando o nome a um tipo de cerveja, as Abadias. Nos mosteiros, havia conhecimento, desenvolvimento de técnicas e 
capacidade de registros das receitas. Neste sentido, pode-se falar em acumulação e distribuição do conhecimento, mesmo que em escala menor para aquele grupo restrito dos abades. Estes foram os primeiros pesquisadores sobre a cerveja, aprimorando seu método de fabricação e introduzindo a inovação de conservação a frio da bebida.

No Século XIV, para manter a qualidade da cerveja, foi promulgada uma lei, a Reinheitsgebot (Lei da Pureza da Cerveja), pelo Duque Guilherme IV da Baviera, em 23 de abril de 1516. Este instituiu que a cerveja deveria ser fabricada somente com os seguintes ingredientes: água, malte de cevada e lúpulo (a levedura de cerveja não era conhecida à época). Isto se constitui em um dos mais antigos decretos alimentares da Europa, que perdura até hoje na Alemanha. Ainda é uma referência usada para indicar a alta qualidade do produto cerveja e em campanhas de divulgação com este "selo" de garantia, embora tenha perdido força em função da pressão de mercado para introdução de novos ingredientes.

No Século XIX, o ressurgimento do valor da cerveja veio com os avanços tecnológicos e a mudança no processo de produção industrial. As exigências de se produzir cerveja apenas no inverno e guardá-las para consumo no verão, propiciou o surgimento da chamada cerveja tipo Lager ("guardada, armazenada"), com características de sabor mais acentuado e aparência clara e leve: era a descoberta da fermentação a frio. Na época, não se conhecia as leveduras, que tornavam estas cervejas diferentes, e acreditava-se que houve mutação dos micro-organismos da fermentação.

Nos Séculos XX e XXI, a cultura cervejeira apresentou grande crescimento. O desenvolvimento tecnológico, o renascimento da produção caseira de cerveja (homebrewing) e a nova geração de microcervejarias pelo mundo trazem inovações aos consumidores, por meio da oferta de produtos de qualidade e diversificados. Já podem ser encontradas cervejas de boa qualidade, que era de acesso a um público restrito há poucos anos atrás.

\subsection{Processo de produção da cerveja e inovação}

Para a produção da cerveja, a cevada maltada é moída e colocada em infusão; depois é coada, fervida com lúpulo e novamente coada. Acrescenta-se levedura e deixa-se fermentar. Essa mistura, o mosto, é deixada em repouso para maturação. A levedura é separada do mosto e estará pronta para ser consumida após alguns dias de "descanso". Esse processo requer muito conhecimento e prática, pois envolve várias e complexas reações químicas e bioquímicas que devem ocorrer sob rigoroso controle (MORADO, 2009, p.126). De acordo com Tschope (2001), a fabricação de cerveja não se constitui apenas como uma técnica e sim como uma tradição milenar.

Uma inovação importante relacionada à cerveja é a introdução do lúpulo na composição do produto no Século IX, levando a um melhor controle da produção e conservação da bebida. De produção caseira para 
consumo da família, a bebida passa a ter status de negócio com características de uma "indústria rudimentar" na estrutura social da época, que se iniciava com a aglomeração das pessoas em vilas e pequenas cidades.

Outra inovação no processo produtivo foi a utilização do coque para a secagem do malte, que permitia que os grãos não fossem torrados e não tivessem cheiro de fumaça, produzindo, assim, uma cerveja mais clara.

A cerveja Pilsen surgiu devido a inovações na produção implantadas pelo mestre cervejeiro Josef Groll, que dominava os novos conhecimentos de secagem e conseguiu fazer uma cerveja clara, que, combinada com a vocação de produtores dos cristais da Boêmia, "caiu no gosto" dos apreciadores da cor, brilho e do colarinho da nova cerveja.

\subsection{Atores na produção de cervejas especiais}

Retornando à definição de Morado (2009, p. 264), existem vários tipos de cervejarias. As megacervejarias produzem mais de um terço da produção mundial de cervejas, principalmente as Pilsen. Microcervejarias é um termo que surgiu recentemente para designar empreendimentos que visam produzir cerveja com diferencial local, atendendo a argumentos de tradição e/ou qualidade diferenciada, não se preocupando com a questão da produção industrial. As nanocervejarias têm os mesmos objetivos das microcervejarias, mas sem as exigências tributárias e fiscais exigidas pelo governo ao microempresário. Outro importante tipo são as homebrewing ou produtores caseiros que fazem a sua cerveja, a princípio pelo prazer da produção, posteriormente para troca de experiências e compartilhar conhecimento, associado à gastronomia e evitando a massificação.

Essa questão da massificação é discutida por Pine II (1994), ao apresentar o conceito de customização maciça, em oposição à produção em massa, que pode auxiliar no entendimento do crescimento de produção e no consumo das cervejas artesanais. Na produção em massa, eram regras: os produtos padronizados, os mercados homogêneos, o longo ciclo de vida e o desenvolvimento de produtos. Hoje, a variedade e a personalização suplantam produtos padronizados e surgem mercados heterogêneos e fragmentados.

A justificativa para estas mudanças são as alterações nas necessidades e vontades dos consumidores, e especialmente mudanças demográficas. Os fabricantes criaram diversos produtos que atendessem aos diferentes estilos de vida e personalidade de seus consumidores. Para os mais exigentes, as microcervejarias e nanocervejarias buscam atendêlos com produtos de menor escala, mas de alto valor agregado.

O produto cerveja, existente há séculos no mundo, pode ser considerado apenas como uma técnica de produção já conhecida e controlada? Para responder a isto, o tópico a seguir apresenta uma discussão sobre o processo de inovação. 


\section{0 processo de inovação}

A inovação, muito mais que uma ferramenta gerencial, algo passageiro ou modismo, é essencial para o entendimento de crescimento e perenidade nas empresas (TIDD et al., 2008, p. 10).

\subsection{A necessidade de uma definição do conceito}

Inovação é um conceito tratado mundialmente e se relaciona com a competitividade e a perenidade dos empreendimentos, podendo ser conceituada como "uma atividade complexa, diversificada, em que vários componentes interagem e que as fontes de dados têm de refletir este fato" (OECD, 2005, p.17).

Schumpeter $(1982 \text {, p. } 144)^{7}$ discorre sobre o ciclo econômico e afirma que o mesmo não se dá de forma contínua e gradual, mas de maneira contraditória, com incidentes, propostas contrárias e contratempos. O autor fala, ainda, sobre a importância da inovação na teoria da mudança econômica:

Quando as indústrias têm expansão da atividade na prática corrente, seja por necessidade de aumento da população ou tarifas protecionistas, diz que tem uma "resposta adaptativa". E sempre que a economia como um todo, ou dada indústria ou algumas empresas do setor fazem qualquer coisa diferente, qualquer coisa que esteja fora do âmbito das práticas existentes, podemos falar de resposta criativa (SCHUMPETER, 1996, p. 203).

Segundo Schumpeter (1996), para que a resposta criativa ocorra, três características são necessárias:

a) Do ponto de vista do observador, que domina todos os fatos relevantes, somente pode ser compreendida ex post;

b) A resposta criativa modela todo o curso de acontecimentos subsequentes e seu resultado em longo prazo, por isto é essencial no processo histórico; e

c) A resposta criativa depende de qualidade das pessoas disponíveis em uma sociedade, qualidade relativa das pessoas em dado campo de atividade relativa à qualidade existente e com as decisões individuais, ações e padrões de comportamento.

Para Schumpeter $(1996)^{8}$, a invenção é uma nova ideia criada e que possui potencial para exploração comercial, enquanto inovação baseia-se na mesma ideia quando explorada comercialmente de qualquer forma.

Original em alemão Theorie der Wirtschatftlichen Entwicklung em 1964

Original em inglês: Essays: On Entrepeuneurs Innovation, Business Cycles, and the Evolutioun of Capitalism 1989. 
Pode-se dizer que a visão de Schumpeter, sobre a inovação e o empresário, influenciou os trabalhos de outros autores sobre inovação, o empreendedor e sua função na sociedade moderna, a exemplo de Drucker (1987), Tigre (2006), Tidd et al. (2008), dentre outros.

Drucker (1987, p. 35) concorda com o pensamento de Schumpeter, que postulava sobre o desequilíbrio dinâmico provocado pelo empreendedor inovador, em vez de equilíbrio e otimização. O desequilíbrio é a "norma" de uma economia sadia e a realidade central para a teoria e a prática econômica.

\subsection{Tipologia de inovação adotada}

Diversas são as tipologias sobre inovação. Os autores pesquisados apresentam-nas de acordo com o enfoque de inovação adotado sobre o tema. Embora se encontre diversas tipologias, existem muitas semelhanças entre elas. O que pode ser notado na literatura pesquisada é que, possivelmente, os autores se inspiraram nas mesmas fontes teóricas.

A tipologia adotada inicialmente por Tidd et al. (2008, p.30), busca quatro categorias abrangentes para classificar inovação: inovação do produto; inovação de processo inovação de posição e inovação de paradigma - mudanças nos modelos mentais subjacentes que orientam 0 que a empresa faz.

De acordo com Tidd et al. (2008 p. 31-32), as inovações incrementais e radicais trabalham na dimensão do grau de novidade envolvida. As primeiras ocorrem em maior freqüência, em relação às inovações radicais. Estas causam uma mudança descontínua e são importantes na gestão da qualidade total e na eficiência a longo prazo.

Pode-se classificar as inovações por seu grau de inovação e extensão das mudanças que havia antes. Conforme a taxonomia de Freeman (1997) apud Tigre (2006), os tipos de mudanças das inovações podem ser dividas em incremental; radical; novo sistema tecnológico; e novo paradigma tecnoeconômico.

Uma teoria sobre a inovação descontínua é defendida por Christensen (2001), chamada de "inovação por ruptura". Em certos casos, como o exemplo das indústrias de disco rígido, o mercado é o verdadeiro gatilho da inovação, pois mostra as falhas de grandes empresas bemsucedidas que não deram a atenção devida à nova tecnologia, aos novos mercados com suas necessidades e expectativas muito diferentes dos existentes e, assim, faliram. Os cinco princípios de uma inovação de ruptura apresentados por Christensen são base para o "dilema da inovação", nas quais as empresas devem atentar aos seus sinais para não ocorrer insucesso: 1- As companhias dependem de clientes e investidores para gerar recursos; 2- Mercados pequenos não solucionam a necessidade de crescimento de grandes empresas; 3- Mercados que não existem não podem ser analisados; 4- A capacidade de uma organização define suas incapacidades; e 5- O abastecimento de tecnologia pode não ser igual à demanda de mercado. 
Verifica-se em Tidd et a.l (2008), que um ponto bastante comum entre os pesquisadores do tema inovação é a concordância quanto à classificação em inovação incremental e radical.

\subsection{O Processo de inovação versus gestão da inovação}

A necessidade de gerenciar a inovação é um dos grandes desafios dos empreendedores. Tidd et al. (2008) afirmam que a gestão da inovação é "difícil e arriscada", uma vez que a maioria das inovações não se torna sucesso comercial.

Outro desafio de gestão é o entendimento das pessoas sobre o termo inovação. Para isto, faz-se necessário definir muito bem este conceito, entendendo-o como "um processo de fazer de uma oportunidade uma nova ideia e de colocá-la em uso da maneira mais ampla possível" (Tidd et al., 2008, p. 86).

O processo de inovação ocorre da mesma forma em todas as empresas, segundo Tidd et al. (2008, p.87). O buscar é analisar o cenário à procura de ameaças e oportunidades para a mudança. O item selecionar é decidir, entre os sinais apresentados no cenário, a qual deles irá responder. $\mathrm{E}$, finalmente, implementar é traduzir a ideia nova em algo novo e lançar no mercado. Para a fase de implementação de uma inovação são necessárias algumas etapas importantes: a aquisição de conhecimento para a inovação; execução do projeto sob condições de imprevisibilidade; lançamento da inovação no mercado e o seu gerenciamento inicial; e sustentabilidade de adoção e o uso da inovação a longo prazo.

As pequenas empresas e empreendedores também precisam se preocupar com o processo de inovação e com sua posição de mercado. Apesar de elas apresentarem algumas vantagens sobre as grandes, como agilidade e rapidez de decisão, têm limitações de recursos que demandam mais criatividade na implantação da inovação. As pesquisas sobre inovação em pequenas empresas são mais escassas e, na sua maioria ocorrem em empresas de alta tecnologia. Tidd et al. (2008, p. 567) apresentam resultados de uma pesquisa realizada no Reino Unido, na qual as pequenas empresas apresentam algumas características semelhantes: envolvem, mais provavelmente, na inovação de produto, em vez de processo; são centradas em produtos para mercados de nicho; são mais comuns entre produtores de produtos finais; envolvem, com frequência, alguma forma de ligação externa; e tendem a ser associadas a crescimento de produção e emprego. As características relativas à inovação de produto e centralização em um mercado de nicho específico são importantes na análise da presente pesquisa.

No Brasil, pesquisas mostraram que os cinco principais fatores de sucesso das pequenas e médias empresas são: bom conhecimento de mercado, boa estratégia de vendas, criatividade do empresário, aproveitamento de oportunidades de negócio, ter acesso as novas 
tecnologias e capacidades de assumir riscos. Estes fatores são constatações do processo inovativo (VASCONCELOS, 2008).

Identificado o processo de inovação, outra questão é: como medilo? A existência de um processo contínuo de inovação leva a necessidade de mensurar os resultados obtidos.

Alguns indicadores propostos para cada uma das perspectivas são bem objetivos, tais como crescimento de vendas, percentual de produtos inovadores sobre o total do faturamento, novos clientes, melhoria do processo e desempenho de produto. Outros não são tão objetivos, mas devem ser mensurados como satisfação dos clientes e comprometimento dos funcionários. No Brasil, estudos sobre a inovação do setor cervejeiro são mais direcionados às grandes empresas. Os indicadores e as publicações encontradas tendem a agrupar a indústria de bebidas com a de alimentos, alegando que são consideradas indústrias próximas, já que ambas se destinam à nutrição humana (BORBA; JANNUZZI, 2009). Este agrupamento tende a mascarar alguns indicadores e diferenças entre os setores, pois o de alimentos chega a ser oito vezes maior que o de bebidas.

\section{Metodologia}

Quanto aos fins, esta pesquisa foi classificada como descritiva e aplicada. Quanto aos meios, foi realizada uma análise documental e de campo, que foi projetada para aplicar as descobertas a um problema específico em que se analisaram, qualitativamente, as características do processo de inovação das cervejas especiais da RMBH (COLLIS; HUSSEY, 2005).

A identificação do processo de inovação em cervejas especiais foi realizada a partir do paradigma interpretativo. Collis e Hussey (2005) apresentam algumas características desse paradigma interpretativo que condiz com a opção de pesquisa em questão, como a produção dos dados qualitativos e análise em profundidade no ambiente no qual é localizado.

A primeira etapa da pesquisa constitui-se no levantamento bibliográfico sobre inovação e cervejas especiais produzido nos últimos 10 anos.

A unidade de análise para a pesquisa foi o setor de cervejas especiais da Região Metropolitana de Belo Horizonte. As unidades de observação foram os especialistas em cervejas especiais, ou seja, empresários do setor, homebrewers, mestre cervejeiro, consultores e representante do sindicato patronal de bebidas e eventos do setor, no total de oito profissionais. Estes profissionais foram escolhidos pelo critério de acessibilidade e por terem produtos distribuídos em locais de revenda de cervejas artesanais, postos de autosserviço, bares, livro publicado e representatividade no setor. A identificação dos atores foi feita através de sites representativos do setor, como a Acerva Mineira e o Pão \& Cerveja, que é um programa de entrevistas na rádio $C B N$, transmitido todas as sextas-feiras, sendo canal de geração de notícias da cultura cervejeira. 
Uma referência importante também foi o livro Larousse da Cerveja (MORADO, 2009) e o site do autor, que categoriza os principais players em cervejas especiais.

Um dos instrumentos de pesquisa escolhidos para obtenção dos dados foi a entrevista semiestruturada, que é um método apropriado para se entender qual é o construto utilizado pelo entrevistado como base para as suas opiniões e visões sobre a questão estudada (LOWE, 1991 apud COLLIS; HUSSEY, 2005). Vale ressaltar que foram usados, para as entrevistas, três roteiros diferentes, mas todos com questões que versavam sobre a percepção dos atores sobre o tema inovação. Foram necessários os três tipos de entrevistas porque o volume da produção de cervejas especiais é diferente entre os três tipos de atores, ou seja, o micro e o nanocervejeiros têm um volume de produção acima de 300 litros. Homebrewers produzem em menor volume (até 80 litros) e os consultores e representantes sindicais não são produtores de cerveja.

Além das entrevistas, foi também utilizada a técnica da observação não participante em ambiente natural (COLLIS; HUSSEY, 2005), com o objetivo de registrar o que as pessoas fazem em termos de suas ações e de seu comportamento, sem o envolvimento do pesquisador. A observação foi realizada em uma mesa redonda do setor cervejeiro e em um painel setorial do INMETRO, ocorridas em 28 de maio e em 26 de agosto de 2010 no Rio de Janeiro, registrando-se os dizeres das pessoas por meio de gravação em áudio.

Para aferição do instrumento de pesquisa, realizou-se um pré-teste com um empresário de microcervejaria. O pré-teste realizado permitiu adequação do instrumento aos objetivos da pesquisa, definindo uma entrevista mais focada e com menos perguntas para cada ator que atuava em cervejas especiais.

Quanto ao processo de inovação verificou-se os indicadores dos processos de buscar, selecionar, implementar as inovações, bem como a aprendizagem advinda do mesmo, através das entrevistas, suportados pelo modelo de Tidd et al. (2008).

\section{Análise dos resultados}

Este item apresenta os resultados obtidos na pesquisa, divididos em quatro itens: a) identificação dos principais atores envolvidos em cervejas especiais da $\mathrm{RMBH}$; b) o processo de fabricação de cervejas especiais realizados por estes atores; c) a existência de inovação em cervejas especiais; e d) a contribuição destes atores ao acúmulo do conhecimento na produção de cervejas especiais e sua respectiva disseminação.

\subsection{Identificação dos principais atores}

Para se analisar como ocorre a inovação no setor e procurando-se compreender quais são suas implicações para o mundo cervejeiro, foram identificados os principais atores do segmento de cervejas especiais. Esta identificação deu-se por meio da busca em sites e na literatura, mesmo 
sendo escassa, conforme declararam os próprios entrevistados: "[...] Sobre produção técnica não tem no Brasil. As pessoas que ministram cursos montam as apostilas sendo uma compilação do aprendizado na prática. Hoje temos sites, blogs, cursos, publicação ainda não tem [...]".

Outra forma de identificar esses atores foi a observação não participante de uma mesa redonda "Revolução das Cervejas Especiais no Brasil", ocorrida na Expo Cachaça em 28 de maio de 2010, técnica metodológica definida por Collis e Hussey (2005, p. 163). Nesse evento, foram apresentados os principais atores do segmento de cervejas especiais de Minas Gerais e alguns representantes de outros estados.

Observou-se que os principais atores atuantes no negócio de cervejas especiais são os microcervejeiros, os nanocervejeiros, os homebrewers, consultores, especialistas, mestres cervejeiros e representantes do sindicato patronal do setor de bebidas.

Entre os entrevistados, identifica-se o espírito empreendedor que, sob o ponto de vista de Dornelas (2008, p. 9), "no Brasil, ser bemsucedido como empreendedor não é tarefa fácil, mas aqueles que conseguem tornam-se referência pela ousadia, criatividade, inovação e persistência." Isso pode ser identificado nos depoimentos da pesquisa:

[...] Percebi que fazia um produto muito similar à cerveja alemã, que a minha tinha respaldo técnico para ser tão boa. Procurei por cursos na Alemanha, Bélgica e Dinamarca. Voltando ao Brasil associei-me aos meus irmãos com ideia de fazer um futuro empreendimento, e passamos a pesquisar juntos. Estudamos a fundo o mercado de microcervejarias e começamos a estudar o mercado no Brasil que era promissor, mas muito incipiente em 2000 [...].

"[...] A grande maioria dos homebrewers gosta de fazer cerveja pelo prazer de produzir um produto de qualidade que possa compartilhar com amigos e família, é um hobby $[\ldots]^{\prime \prime}$.

Embora não se tenha números, é possível localizar os atores em cervejas especiais da RMBH através de sites, de eventos e de literatura da área. Em geral, são pessoas que iniciaram a fabricação de cervejas de forma caseira, pelo prazer da degustação. Apesar de se observar uma produção pequena, estes atores mostram-se empreendedores e inovadores.

\subsection{0 processo de fabricação de cervejas especiais}

Para se analisar como ocorre a inovação nesse setor, foi necessário conhecer o processo de fabricação de cervejas especiais, procurando-se identificar se existem inovações na forma de fazer esta cerveja. 0 processo de produção da cerveja é bastante simples, conforme citado por Morado (2009) e Tschope (2001), embora seja de difícil execução pela necessidade de muito conhecimento e prática.

$\mathrm{Na}$ pesquisa documental, foram encontradas, em diversos sites cervejeiros, receitas e formas de se produzir cerveja, inclusive com 
programas para cálculos de IBU (unidade de medida de amargor) e ABV (unidade de teor alcoólico da bebida).

Foi possível observar que um dos diferenciais nas cervejas especiais é o cuidado com o preparo e a seleção de matéria prima de alta qualidade, o que corrobora o pensamento de Tschope (2001, p. 17).

A busca pela diferenciação é o que distingue as cervejas especiais das cervejas produzidas em massa, mesmo sendo o processo de fabricação idêntico. Constata-se isso na afirmação de um dos entrevistados: "[...] É uma arte milenar o que se tem feito é o resgate da arte. As grandes cervejarias trabalham com padronização do processo com menos sabor e para atingir o maior número de pessoas [...]". "[...] fazer uma cerveja procurando trazer para o lado das cervejas especiais. Fazer uma ponte de uma cerveja nem tão complexa, mas também nem tão simples, mas que os consumidores saibam e percebam que seja diferenciada $[\ldots] "$. .

Resumindo, pode-se constatar que a produção da cerveja especial é simples, mas seu preparo é cuidadoso e exige qualidade na seleção da matéria prima e a adição de produtos regionais que dão uma ideia de aproveitamento da especificidade local-global dos territórios, isto é, a inserção do componente denominado terroir (torrão), que adiciona valor aos produtos alimentares e artesanais a partir do conjunto de peculiaridades edafo-climáticas, cultura e know-how que os singularizam (KRUCKEN, 2009; SMERALDI, 2009). Prima-se pela diferenciação, o que gera, consequentemente, a inovação incremental do processo.

\subsection{O processo de inovação em cervejas especiais}

Seguindo as sugestões do Manual de Oslo (OECD, 2005, p. 54), o requisito mínimo para se definir uma inovação é que o produto, o processo, o método de marketing ou organizacional sejam novos - ou significativamente melhorados - para a empresa, o mercado ou para o mundo. São as Inovações Tecnológicas em Produtos e Processos (TPP) que compreendem as implantações de produtos e processos tecnologicamente novos e substanciais melhorias tecnológicas. Com base nestas definições, foi possível verificar a existência de processos de inovação em cervejas especiais.

Muitos afirmaram que não criaram nada novo, na produção da cerveja. Já existiam as receitas das cervejas, mas nota-se que há relatos de algumas "mudanças". "[...] Eu sigo escolas cervejeiras alemãs, belgas, ingleses para ter um parâmetro, porém coloco meu lado. Tem cerveja que eu coloco mel, melaço, açúcar mascavo, para dar personalidade à cerveja. Fere um pouco as escolas cervejeiras, mas estou inovando, saindo da mesmice $[\ldots]^{\prime \prime}$

Podem-se definir essas mudanças de acordo com o conceito de inovação de produto, resumidamente apresentado como mudanças nas coisas - produtos/serviços - que uma empresa oferece (TIDD et al., 2008). Esse conceito também é apresentado no Manual de Oslo (OEDC, 
2005), como sendo a introdução de um bem novo ou significativamente melhorado no que concerne a suas características ou usos previstos. Incluem-se melhoramentos significativos em especificações técnicas, componentes...

[...] No Brasil tem ocorrido um fenômeno interessante e rico, e que as microcervejarias 'autênticas', cuidando da expansão e da cultura cervejeira, estão desenvolvendo algumas cervejas com ingredientes tipicamente nacionais, como jabuticaba, mandioca e rapadura isto é Inovação da receita. Alguns inovando na técnica de depurar o malte para tirar óleos e fazer cerveja menos ácida ou mais doce [...].

O resultado deste item da pesquisa pode ser corroborado pelos estudos de Bhaskaran (2006), cujos resultados indicam que a inovação incremental oferece importantes vantagens competitivas para as empresas de pequeno e médio porte. Empresas estas que estão em consonância com as propostas por Tidd et al. (2008) em inovações incrementais, as quais podem ser adotadas rapidamente $e$ operacionalizadas pelos empresários de diferentes origens culturais e habilidades.

Verificou-se, parcialmente, a existência de inovação em marketing no universo das cervejas especiais. Adotou-se o conceito de que as inovações de marketing são voltadas para melhor atender às necessidades dos consumidores, abrindo novos mercados, ou reposicionando o produto de uma empresa no mercado, com o objetivo de aumentar as vendas (OECD, 2005). A maioria dos homebrewers entrevistados tem uma visão interessante, principalmente quando se investiga quais estratégias de marketing utilizam para criar e comercializar uma nova cerveja. O ponto mais ressaltado é a diferenciação e a exclusividade, que busca atender ao consumidor.

Outro aspecto observado é o cuidado com o visual da marca e o uso da internet, principalmente as redes sociais, para divulgação e comercialização do produto. As redes sociais parecem ter um papel fundamental nesta nova forma de relacionamento com os consumidores de cervejas especiais, levando à ideia de mobilização descolada, citada por Rao (2010). Conforme os depoimentos de entrevistado:

[...] Canais de distribuição própria por telefone, e-mail. O blog, Twitter e Facebook da cerveja como canais diretos de relacionamento com a marca e também pode fazer pedido. Faço promoção no Twitter de harmonização com pratos junto ao restaurante e para divulgar e batizar uma nova cerveja [...]

Quando o foco das questões é o consumidor, a consciência, acerca da importância do marketing, aumenta, tanto para o grupo de empresários do setor, quanto para homebrewer e consultores. Os relatos podem ser corroborados com duas das estratégias propostas por Porter (2004), dentre as quatro estratégias genéricas de mercado que as empresas devem escolher: 
O ponto que mais chama a atenção sobre a questão de marketing é o cuidado com a diferenciação do produto e a disseminação de uma ideia como o "beer evangelismo" (conforme denominação de RAO, 2010), por meio de eventos e as redes sociais como o Twitter. A pesquisa comprova quatro dos cinco principais fatores de sucesso das pequenas e médias empresas no Brasil, considerados por Vasconcelos (2008), a saber: bom conhecimento de mercado, boa estratégia de vendas, criatividade do empresário e aproveitamento de oportunidades de negócio.

Pôde-se verificar, na pesquisa, a existência de inovações incrementais ligadas ao produto cerveja artesanal, mas não foram observadas inovações radicais.

O processo de inovação existente não é explicitado abertamente pelos entrevistados, embora a maioria realize ações inovadoras como adaptação de maquinários, introdução de produtos à cerveja, nova forma de se fazer a cerveja e, mesmo, o uso de redes sociais como forma de marketing.

Portanto, a inovação predominante incremental está presente no setor de cervejas artesanais, necessitando-se de maior conscientização sobre o tema como potencial de utilização dos processos de inovação para o crescimento do setor. É uma inovação tanto para as empresas, que buscam a diferenciação, quanto para o mercado, pois influencia no comportamento do consumidor, que busca novidades e produtos exclusivos.

\subsection{A acúmulo e disseminação do conhecimento na produção de cervejas especiais}

Verificou-se que a bibliografia sobre o tema é escassa, não somente no Brasil, mas também no exterior, segundo consultores e microcervejeiros entrevistados. "[...] O conhecimento sobre a cerveja especial pode ser obtido através da internet e livros importados [...]". "[...] Sobre produção técnica não tem no Brasil. As pessoas que ministram cursos e montam apostilas fazem compilação do aprendizado na prática $[\ldots]^{\prime \prime}$.

Sabe-se que a inovação é movida pela habilidade de manter relações (TIDD et al., 2008). Neste sentido, a Acerva Mineira, sendo uma associação dos cervejeiros, promove a aquisição e 0 acúmulo de conhecimentos no Estado, tendo um papel importante de formação e difusão da cultura cervejeira $e$, consequentemente, no processo de inovação.

Verificou-se, desta maneira, que o acúmulo de conhecimento está presente nos processos de inovação das cervejas especiais. Além disso, a transformação de conhecimento tácito em explícito é possível por meio da associação em rede na Acerva e nas listas de discussões, como troca de conhecimento técnico e experimentação. 


\section{Conclusões}

O estudo realizado buscou analisar como ocorre a inovação no setor de cervejas especiais na Região Metropolitana de Belo Horizonte, procurando-se compreender quais são suas implicações para o setor de cervejas. Para atender ao objetivo principal proposto, foi necessário responder cada um dos quatro objetivos específicos.

O primeiro objetivo propôs identificar os principais atores envolvidos em cervejas especiais da RMBH. Este objetivo foi alcançado; embora não se saiba precisamente quantos são, foi possível localizar os principais atores em cervejas especiais da $\mathrm{RMBH}$, através de sites, de eventos do setor e de literatura da área, ainda que limitada. Em geral, esses atores iniciaram a fabricação de cervejas de forma caseira, pelo prazer da degustação. Apesar de se observar uma produção pequena desses produtores, estes se mostram empreendedores e inovadores corroborando o pensamento do mestre-cervejeiro Tschope (2001), o qual afirma que os atores das cervejas artesanais são pessoas que buscam experienciar algo mais exclusivo ao seu paladar.

Portanto, os atores em cervejas especiais identificados pela pesquisa são indivíduos empreendedores e que não desistem do negócio (DORNELAS, 2008). Geralmente, buscam uma qualidade de vida condizente com a cultura cervejeira, são extremamente sociáveis e tendem a crescer, em número, em Minas Gerais e no Brasil, a exemplo do que já ocorre nos Estados Unidos. Os mesmos participam de redes sociais, listas de discussão e promovem encontros para degustarem e fabricarem a sua cerveja.

O segundo objetivo específico visou o conhecimento do processo de fabricação de cervejas especiais realizados por estes atores. Pode-se constatar, por meio das entrevistas e visita in loco, que a produção da cerveja especial é simples, conforme afirmam alguns dos autores (MORADO, 2009), mas seu preparo é cuidadoso e exige qualidade na seleção da matéria prima e muita atenção. Prima-se pela diferenciação, o que gera, consequentemente, a inovação do processo conforme a tipologia adotada inicialmente por Tidd et al. (2008), pela qual a inovação do processo existe quando há mudanças na forma como produtos/serviços são criados.

Vale ressaltar que alteração no processo de produção de cerveja artesanal é incremental sob o ponto de vista de Freeman (1997). O tipo de mudança das inovações incrementais tem como características os melhoramentos e modificações cotidianas. Observam-se novidades quanto ao seu processo de fabricação, ao acréscimo de produtos e nas melhorias técnicas para otimizá-los entre os produtores de cervejas especiais entrevistados.

O terceiro objetivo específico foi verificar se existem processos de inovação em cervejas especiais, objeto central deste estudo, de acordo com a definição de Tidd et al. (2008). Outra teoria adotada diz respeito às orientações propostas no Manual de Oslo (OECD, 2005) quanto a uma 
inovação, ou seja, inovações de produto, de processo e de marketing. Para isto, foram realizadas e gravadas entrevistas individuais com os atores identificados, de acordo com o primeiro objetivo, utilizando-se um roteiro semiestruturado para cada tipo de entrevistado. Verificaram-se inovações incrementais ligadas ao produto cerveja artesanal, mas não se pode falar em inovações radicais na concepção de Freeman (1997), pois o produto continua sendo o mesmo, ou seja, cerveja.

Quanto ao processo de inovação, foi possível verificar as três etapas do modelo proposto por Tidd et al. (2008), de buscar ameaças e oportunidades para a mudança; selecionar, entre os sinais apresentados no cenário, a qual deles a empresa irá responder e implementar a ideia nova, em algo novo, e lançar no mercado. Estas etapas foram identificadas por meio dos relatos dos entrevistados, com foco nas microcervejarias.

Em alguns momentos, foi possível observar que o processo de inovação existente não é consciente para a maioria dos entrevistados. A maioria, entretanto, realiza ações inovadoras como adaptação de maquinários, introdução de produtos locais à cerveja, nova forma de se fazer a cerveja e, mesmo, o uso mais intensivo de redes sociais e sites direcionados como forma de marketing. Portanto, a inovação predominantemente incremental está presente no setor de cervejas artesanais, necessitando de maior conscientização sobre este tema, como potencial de utilização dos processos de inovação para o crescimento do setor.

O quarto objetivo foi verificar a contribuição dos atores ao desenvolvimento e acúmulo do conhecimento na produção de cervejas especiais, e respectiva disseminação. Os resultados mostraram que os atores estão em concordância com as formas propostas por Bessant \& Tidd (2009) que afirmam que o conhecimento pode ser adquirido pela experiência, aquisição ou experimentação.

Verificou-se que a bibliografia sobre o tema é escassa, não somente no Brasil, mas também no exterior, segundo os próprios entrevistados, não havendo muito material publicado. Falta uma formação mais acadêmica ou tecnológica para o setor. O conhecimento sobre a cerveja especial tem sido obtido através de meios eletrônicos, como a internet, e o contato com outros cervejeiros, tanto presencialmente quanto em redes de cooperação mundiais, através de listas de discussão com os maiores cervejeiros do mundo.

O setor de cervejas especiais da RMBH se mostra unido e sempre disposto a trocar experiências com aqueles que estejam associados a ele. Promovem concursos, encontros e comemoram datas relacionadas às cervejas, incentivando a AcervA Mineira, uma associação dos cervejeiros que promove a aquisição, o acúmulo de conhecimentos, a divulgação da cultura cervejeira e que, consequentemente, impacta o processo de inovação. Uma forma de movimentar a inovação é pela habilidade de manter relações (TIDD et al., 2008), prática que foi constatada entre os cervejeiros pesquisados. 
Verificou-se, desta maneira, que o acúmulo de conhecimento está presente nos processos de inovação das cervejas especiais, e que a transformação de conhecimento tácito em explícito é possível por meio da associação em redes sociais e uso intensivo dos meios eletrônicos como forma de troca de conhecimento técnico e experimentação. Esta formação em rede é uma forma de promoção e difusão da inovação (RAO, 2010).

Os resultados da pesquisa mostraram fortes evidências da ocorrência de inovação no setor cervejeiro artesanal, sendo este propício para as incrementais. Estas inovações podem gerar diferenciais competitivos importantes aos que sabem reconhecê-la e geri-la.

Mediante tais conclusões, considera-se que o objetivo principal da pesquisa, qual seja, analisar como ocorre a inovação no setor de cervejas especiais, na região metropolitana de Belo Horizonte, foi atingido, a partir do caráter descritivo do estudo.

Como sugestão de futuras pesquisas, observa-se que o setor carece de indicadores econômicos e dados estatísticos mais consistentes que retratem o segmento cervejeiro artesanal, sendo esta uma possibilidade interessante de pesquisa, isto é, uma pesquisa censitária no segmento. Outra via de pesquisa seria estudar a cultura organizacional voltada ao segmento cervejeiro, seus comportamentos, símbolos, linguagem, artefatos e heróis da "cultura cervejeira". Sugere-se analisar o assunto baseando-se em visões e conceitos mais recentes, tais como inovação aberta (open innovation) (CHESBROUGH, 2006) e inovação soft (STONEMAN, 2010), de natureza estético-hedônica.

\section{Referências}

AMERICAN BEVERAGE COMPANY - AMBEV. 2010. Disponível em: <http://www.ambev.com.br/Default.aspx>. Acesso em: 20 mar. 2010.

AMORIM, R. $1^{0}$ CENSO ACERVAS. Disponível em: <http://oglobo.globo.com/blogs/cervejaso>. Acesso em 13 out. 2010.

BHASKARAN, S. Incremental innovation and business performance: small and medium-size food enterprises in a concentrated industry environment - abstract. Journal of Small Business Management, v. 44, n. 1, p. 64-80, $2006 . \quad$ Disponível em: <http://www3.interscience.wiley.com/journal/118609697/abstract>. Acesso em: 27 mar. 2010.

BESSANT, J.; TIDD, J. Inovação e Empreendedorismo. Porto Alegre: Bookman, 2009.

BORBA; E. C. G; JANNUZZI, C. A. S. C. Estratégia de gestão e inovação tecnológica na indústria paulista de fabricação de produtos alimentícios e bebidas. In: ENCONTRO DE INICIAÇÃO CIENTÍFICA DA PUC-CAMPINAS, 14., 2009, Campinas. Anais... Campinas: [s. n.,] 2009.

BRASIL. Agência Nacional de Vigilância Sanitária - Anvisa. Decreto no 2.314, de 4 de setembro de 1997. Regulamenta a Lei no 8.918, de 14 de 
julho de 1994, que dispõe sobre a Padronização, a classificação, o registro, a inspeção, a produção e a fiscalização de bebidas. Diário Oficial da União, Brasília, 5 set. 1997. Disponível em: <http://www.anvisa.gov.br/legis/decretos/2314 97.htm>. Acesso em: 26 mar. 2010.

CHESBROUGH, H. Open innovation: a new paradigm for understanding industrial innovation. In: CHESBROUGH, H.; VANHAVERBEKE, W.; WEST, J. (Eds.). Open innovation: researching a new paradigm. Oxford: Oxford University Press, 2006. p.1-12.

CHRISTENSEN, C. M.. O Dilema da Inovação. São Paulo: Makron Books, 2001.

COLLIS, J.; HUSSEY, R. Pesquisa em administração: um guia prático para alunos de graduação e pós-graduação. Porto Alegre: Bookman, 2005.

DORNELAS, J. C. A. Empreendedorismo: transformando ideias em negócios 3.ed. Rio de Janeiro: Elsevier, 2008.

DRUCKER, P. F. Inovação e empreendedor (entrepreneurship): prática e princípios. 6 ed. São Paulo: Pioneira, 1987.

EASTERBY-SMITH, M.; THORPE, R.; LOWE, A. Management research: an introduction. London: Sage, 1991.

FREEMAN, C.; SOETE, L. The economics of industrial innovation. 3a ed. Cambridge, Mass.: MIT Press, 1997 apud TIGRE, P. B. Gestão da inovação: a economia da tecnologia no Brasil. Rio de Janeiro: Elsevier, 2006.

KRUNCKEN, L. Design e território: valorizando as qualidades dos produtos locais, São Paulo: Nobel, SEBRAE, 2009.

LOWE, 1991 apud COLLIS, J.; HUSSEY, R. Pesquisa em administração: um guia prático para alunos de graduação e pós-graduação. Porto Alegre: Bookman, 2005.

MORADO, R. Larousse da cerveja. São Paulo. Larousse do Brasil, 2009.

ORGANIZAÇÃO PARA COOPERAÇÃO ECONÔMICA E DESENVOLVIMENTO (OECD). Manual de Oslo: diretrizes para coleta e interpretação de dados sobre inovação 3. ed. 2005 Tradução FINEP, 2007.184p. Disponível em: <www.finep.org.br>. Acesso em: 26 mar. 2010.

PINE II, B. J. Personalizando produtos e serviços: customização maciça. São Paulo: Makron Books, 1994.

PORTER, M. E. Estratégia competitiva: técnicas para análise de indústrias e da concorrência. 2. ed. Rio de Janeiro: Elsevier, 2004.

RAO, H. Os revolucionários nos negócios: aprenda com os movimentos sociais a promover inovação em sua empresa. São Paulo: Ed. Gente, 2010. 
SCHUMPETER, J. A. Teoria do desenvolvimento econômico: uma investigação sobre lucros, capital, crédito, juro e ciclo econômico. São Paulo: Abril Cultural, 1982. (Os Economistas).

SCHUMPETER, J. A. Ensaios: empresários, inovação, ciclo de negócio e evolução do capitalismo. Oeiras: Celta Editora, 1996.

STONEMAN, P. Soft innovation: economics, product, aesthetics, and the creative industries New York: Oxford University Press, 2010.

SMERALDI, R. O novo manual de negócios sustentáveis. São Paulo: Publifolha, 2009.

TIDD, J.; BESSANT, J.; PAVITT, K. Gestão da inovação. 3. ed. Porto Alegre: Bookman, 2008.

TIGRE, P. B. Gestão da inovação: a economia da tecnologia no Brasil. Rio de Janeiro: Elsevier, 2006.

TSCHOPE, E. C. Microcervejarias e cervejarias: a história, a arte e a tecnologia. São Paulo: Aden, 2001. 224p.

VASCONCELOS, M. C. R. L. de (2008). A Inovação no Brasil em comparação com a Comunidade Europeia: Uma análise sobre os desafios e oportunidades, com base em indicadores. In: Anais XXV Simpósio de Gestão da Inovação Tecnológica, Brasília, DF, 22 a 24 de outubro. Artigo. Brasília - DF : ANPAD, 2008, 16p.

WARGAFTIG, S. Alimentação engajada. Revista Brasil Sustentável, v. 1 , n. 24, p. 16-17, jun./jul. 2009. 